\title{
Attitudes towards premarital HIV testing among high-school students in the United Arab Emirates, and evaluation of an educational intervention
}

\author{
Maria Ganczak ${ }^{1}$, Peter Barss², Michal Grivna ${ }^{3}$, Marcin Korzeń ${ }^{4}$, Roos Bernsen³ Beata Karakiewicz \\ Fatma Al Maskari ${ }^{3}$ \\ ${ }^{1}$ Department of Epidemiology and Management, Faculty of Medical Sciences, Pomeranian Medical University, Szczecin, Poland \\ ${ }^{2}$ School of Population and Public Health, University of British Columbia, Vancouver, Canada \\ ${ }^{3}$ Institute of Public Health, College of Medicine \& Health Sciences, UAE University, Al Ain, United Arab Emirates \\ ${ }^{4}$ Department of Methods of Artificial Intelligence and Applied Mathematics, Faculty of Computer Science and Information \\ Technology, West Pomeranian University of Technology, Szczecin, Poland \\ ${ }^{5}$ Department of Public Health, Faculty of Medical Sciences, Pomeranian Medical University, Szczecin, Poland
}

\begin{abstract}
Introduction: The aim of the study was to evaluate acceptance of compulsory premarital HIV testing (PHT) among high-school students, and factors associated with support for various options given a positive result, before/after an educational intervention.

Material and methods: A pre-/post-interventional evaluation survey was conducted in 18 randomly selected schools in Al Ain and Abu Dhabi, the United Arab Emirates, before or immediately after a 90 -minute intervention by medical students. Descriptive analysis was completed by SPSS, adjusted odds ratios (OR) using multilevel logistic regression with $\mathrm{R}$.

Results: One thousand nine hundred and three (99.6\%) students participated in the survey (mean age, 17.6 years). Pre-intervention $91 \%$ supported compulsory PHT of a prospective spouse and $9 \%$ left the decision to parents; post-intervention $95 \%$ and $5 \% ; p<0.001$ ). For a positive test, $36 \%$ would openly reveal the prospective spouse's status (32\%, post-intervention). Adjusted by logistic regression, preintervention support to report HIV-positive test result shows correlation with male gender (OR, 1.85), high level of HIV/AIDS knowledge (OR, 1.37), negative attitudes towards PLHIV (OR, 1.47), and Emirati citizenship $(\mathrm{OR}, 1.43)$. Post-intervention, the values were: $0.87,1.72,2.17,0.84$, respectively.

Conclusions: High acceptance of compulsory PHT among young Arabs suggests perceived vulnerability to HIV during marriage. Positive results may be socially isolating. Educational interventions of youth can be effective in reducing HIV-related stigma, and facilitate independent decisions about testing.
\end{abstract}

HIV AIDS Rev 2017; 16, 3: 183-190 DOI: https://doi.org/10.5114/hivar.2017.70946

Key words: premarital, HIV testing, Arab, students, educational intervention.

Address for correspondence: Prof. Michal Grivna, Institute of Public Health, College of Medicine \& Health Sciences, UAE University, P.O. Box 17666, $17666 \mathrm{Al}$ Ain, United Arab Emirates, phone: 37137653 , e-mail:m.grivna@uaeu.ac.ae
Article history:

Received: 21.02.2017

Received in revised form: 28.06.2017

Accepted: 29.06.2017

Available online: 4.10 .2017
International Journal of HIV-Related Problems

HIV \& AIDS

R e v i e w 


\section{Introduction}

Currently, in the United Arab Emirates (UAE) HIV is in a low prevalence stage, similarly to the entire Middle East/ North Africa (MENA) region (0.2\%) [1-5]. From the 1980s to the end of 2012, a cumulative total of 780 HIV still alive cases (76\% males) were reported among 900,000 UAE nationals [2]. These figures represent only the number of officially reported cases, most of which were found through screening in the context of blood donation, pregnancy, premarital testing, and tuberculosis. Epidemiological surveillance among most-at-risk populations, such as intravenous drug users, men having sex with men, and sex workers, is affected by cultural considerations, and is practically non-existent $[2,3]$. Similarly to Saudi Arabia, heterosexuality is the most commonly reported mode of HIV transmission [6].

In the UAE, couples who are planning to marry are required to obtain a compulsory Premarital Medical Screening Report, as mandated by the UAE Personal Status Act No. 28, Article 27 [7]. Compulsory premarital HIV testing (PHT), a subject of this report, was implemented by the Ministry of Health, and has been used for the past 30 years $[2,7,8]$. When HIV is diagnosed, with agreement of the positive individual, the potential couple are informed about treatment possibilities and transmission risks for offspring. Also, HIV infected individuals are reported to police $[8,9]$. HIV-discordant couples are allowed to marry, however, family members and Sharia law could discourage marriage of discordant couples. In 2012, there were $3 \mathrm{HIV}$-positive cases $(0.009 \%$ prevalence) among 33,041 individuals tested during premarital medical screening, similarly to Saudi Arabia $[2,10]$.

Despite the fact that the UAE is a low HIV-prevalence country, the MENA region has the fastest growing HIV epidemic $[3,11]$. Several studies suggest an increase of premarital sex in the whole region, and that it is one of the main transmission routes of HIV $[12,13]$.

A pre-condition for controlling the HIV/AIDS epidemic is creating improved opportunities for testing. However, mandatory PHT remains controversial in terms of social and medical issues, cost effectiveness, and ethics $[8,9]$. Ethical issues include potential discrimination and violation of human rights of infected individuals. Hence, policies on PHT should be subjected to sensible scientific research, balancing the effects on individuals and communities. This has been under research, with information limited to occasional media reports.

The present study was a part of an educational intervention to improve grade 12 Arab student knowledge about HIV and attitudes towards people living with HIV (PLHIV) [14]. Post-intervention, the mean HIV/AIDS knowledge and attitude score improved significantly. This paper considers pre- and post-intervention acceptance of mandatory PHT, attitudes towards HIV-positive individuals, and associated factors of both. The goal is to enhance the research basis for policy on PHT testing and for premarital educational interventions.

\section{Material and methods}

\section{Setting}

The study was conducted between January and March 2006 in two cities of the UAE: Al Ain and Abu Dhabi, with the majority of reported HIV cases [2].

\section{Population and sampling}

The study population consisted of grade 12 students, aged 17-18 years. Because of the composition of the student body at the Medical College of the UAE University, about 75\% female, a field intervention survey was done by three female groups that visited girls' schools, and one group of males who went to boys' schools [14]; the study was performed by medical students, $75 \%$ of whom were female. Multistage stratified sampling was completed of government urban high-schools (10 female, 4 male schools in Al Ain, 4 female in Abu Dhabi), randomly selected from ministry lists. Next, stratified random sampling of classes (25-35 students/class) was done at each school (54 female/16 male classes; two divisions were represented at each school, i.e., arts/science).

Sample size calculations [14] were completed separately for each medical student group, and for females with 3 groups they were conservative. A sample of 450 was sufficient to detect, with power of $80 \%$ and significance of $5 \%$, an absolute difference in positive response to knowledge and attitude questions between subgroups of $15 \%$, provided subgroup distribution was not skewed $>3: 7$. This sample could also demonstrate with the same power and significance, an absolute post-intervention improvement of $10 \%$ in participant subgroups with good knowledge or attitude, assuming that in at most $80 \%$ of participants, the intervention would not change knowledge or attitude.

\section{Study design}

A before-after analytic survey was used, with pre- and immediate post-intervention phases.

\section{Data collection}

A structured, self-administered anonymous questionnaire was adapted for local conditions from a questionnaire used previously in the WHO Health Behavior in School-aged Children Study [15]. It was translated into Arabic and piloted. Relevant to the present paper were the following variables developed for the study: acceptance of mandatory PHT testing (1 item), and students' support for various policies in the event of a positive PHT result (1 item). Regarding acceptance of PHT testing, respondents were asked - if it was their choice rather than a universal policy practiced in the country - they would request a prospective spouse to undergo PHT (Figure 1). Possible answers were: "Request for PHT" or "Leave a decision of PHT to parents". Other previously reported data included demographic (age, sex, nationality, religion), general 


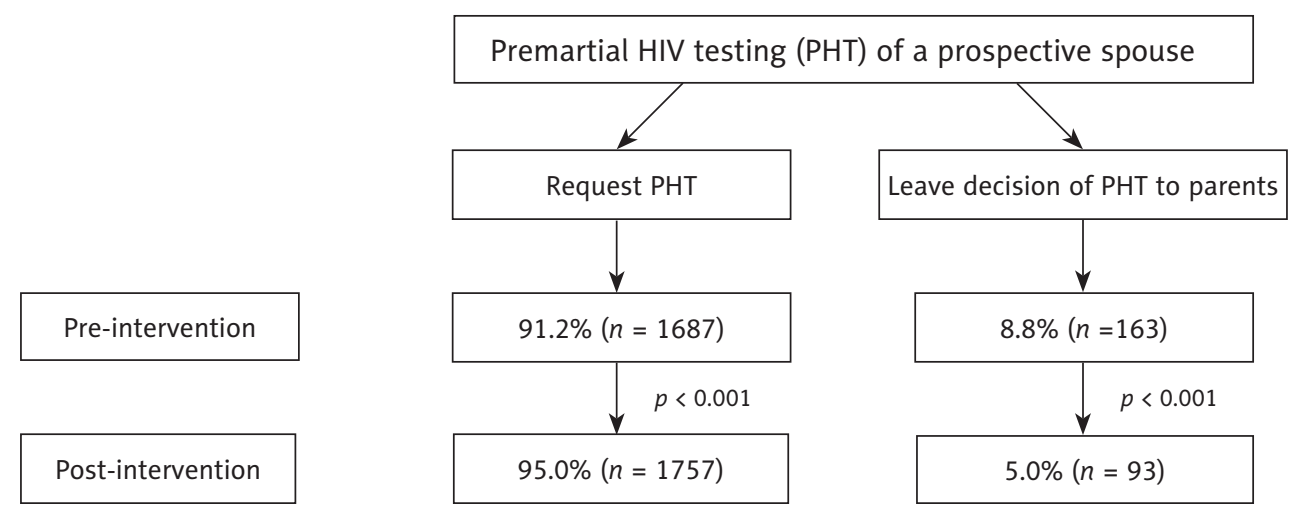

Figure 1. Grade 12 students' attitudes towards premarital HIV testing of a prospective spouse pre- and post-educational intervention, Al Ain and Abu Dhabi cities, United Arab Emirates, $2006(n=1850)$

knowledge about HIV/AIDS (18 items), and attitudes to PLHIV (5 items). The current paper supplements the original analyses of our intervention [14]. For knowledge questions, each correct answer was given 1 point, so higher scores indicated more correct knowledge. For attitude questions, 3 points were given for the most positive attitude, and 0 for the most negative (total, $0-15$ points).

The present research assesses attitudes and preferred policies towards mandatory PHT, before and after a 60-90 minute peer educational intervention. The student educators included 15 final-year medical students from the UAE University, with average age of 23-24 years. Students received a total of 14 hours of training over six days, provided by one of the researchers, an infectious disease specialist, trained by the National AIDS Center in Poland. The intervention included a 30-35 minute factual presentation on HIV/AIDS (prevalence, modes of transmission, clinical symptoms, treatment, prevention), and 3 attitudinal workshops on attitude and stigma (10 minutes each) [14].

The objectives of the HIV/AIDS educational intervention were: a) increase knowledge about HIV/AIDS; b) clarify main modes of transmission; c) provide a realistic appraisal of the risk of contracting HIV to reduce unjustified prejudice towards PLHIV; d) create more positive attitudes; e) facilitate independent decisions about compulsory PHT (the last three were the objectives addressed in this paper).

Before completion of questionnaires, a written consent was obtained from every student.

\section{Data analysis}

Data analysis was conducted using the Statistical Package for Social Sciences Program (SPSS-IBM) and R software [16]. Baseline/post-intervention responses were compared using McNemar's test. Outcome variables, included willingness were:

1. Leaving decisions on PHT to parents.

The participants' decision to use this as an outcome variable was made after broad consultations with medical students and the UAE University staff, as well as based on the literature review. Arab society has been described as "patriarchal" with authoritarian tendencies and with great significance of the family unit, where socio-cultural norms and religious values demand respect of family members and emphasize family relations [17].

2. Public disclosure of prospective spouse HIV seropositivity.

Univariate analysis of demographic characteristics, together with knowledge/attitudes to PLHIV, were associated with major outcome variables of pre-/post-intervention. Significant variables in univariate analysis, guided logistic regression models with $p<0.05$ (cut-off for inclusion). For the outcome variables listed above, two standard logistic models with one outcome were created for pre-/post-intervention. Regression coefficients (betas) were used to assess change in the models. Coefficients for binary variables are equal to the natural logarithm of the odds ratio, $\mathrm{OR}=\exp ($ beta) [18]. Changes in coefficients were compared to assess change in variables. Since students were gathered within classes, intraclass correlation in knowledge/attitudes was a possibility. Since a variable for class was unavailable, "school" and "division" variables were combined to match this variable as closely as possible. Depending on the school, such combinations consisted of 1-3 classes. Finally, multilevel logistic regression was completed with students gathering at the level of individual schools/divisions, and using random intercept with the lme4 package [19]. Ethical approvals were obtained from the UAE University Ethics Committee and Ministry of Education.

\section{Results}

In total, there were 1,903 students participating, and responses were obtained in $99.6 \%$. Mean age: 17.6 years (SD, 0.77 ; range, 15-23). Females constituted of $74 \%$, UAE nationals of $57 \%$, and Muslims of $99 \%$.

\section{Acceptance for PHT of a prospective spouse}

Respondents were asked if they would request a prospective spouse to undergo PHT (Figure 1). Of these, 91\% (95\% CI: $89.8-92.3 \%$ ) agreed with testing, while the other 9\% (95\% CI: 
7.7-10.2\%) would have left the decision to parents. Post-intervention, the proportion in the first subgroup elevated to 95\% (95\% CI: 93.9-95.9\%), and in the second, it was reduced to $5 \%$ (95\% CI: $4.2-6.2 \%) ; p<0.0001$.

Univariate analysis was used to assess demographic characteristics, knowledge of HIV/AIDS, and attitudes towards PLHIV associated with willingness to leave the decision on PHT to parents. Pre-intervention, there were no male/female differences associated with that willingness. Post-intervention, $3.6 \%$ of male $(18 / 505)$ and $5.7 \%$ of female students $(78 / 1,369)$ were willing to leave PHT to parents. Pre-intervention, $6.6 \%(30 / 455)$ of all students with a knowledge score $>75 \%$ were willing to leave PHT to parents, compared to $9.6 \%(136 / 1,416)$ with a score $\leq 75 \%(\mathrm{OR}, 0.68 ; 95 \% \mathrm{CI}$ : $0.44-1.02)$. Post-intervention, data were $4.6 \%(67 / 1,466)$ versus 6.9\% (29/418), OR: 0.64 (95\% CI: 0.34-0.89). Multilevel logistic regression showed that post-intervention, females were more likely to leave decisions on PHT to parents; more knowledgeable students (level $>75 \%$ ) were less likely to leave PHT decision to parents (Table 1). There were no score differences between nationality and attitude $(p>0.06)$ associated with leaving PHT to parents pre-/post-intervention.

\section{Support for various options in the event of a positive PHT result of a prospective spouse}

Students were asked about options in case of a positive PHT result of a prospective spouse (Table 2). The proportion opting for a marriage cancellation with private discussion elevated, while openly revealing the prospective spouse's positive serology option decreased. The proportion to proceed with marriage increased from $5 \%$ to $8 \%$.

Crude/unadjusted support was compared among subjects for stigmatizing versus non stigmatizing decisions. These included reporting the prospective spouse to police or informing the public, versus discussing the issue privately and cancelling the marriage, or proceeding with the marriage.

The age was not a significant factor on this variable pre-/ post-intervention $(p=0.75)$. By gender, pre-intervention $49 \%$ of males $(245 / 505)$ wanted to reveal a prospective spouse's positive HIV test (Table 3). Fewer females (32\%) demonstrated severe attitudes (436 vs. 962), being less often than males (OR, $0.48 ; p<0.001)$ prepared to reveal a prospective spouse's positive test. Post-intervention support of severe attitudes decreased for males, with two times fewer supporters (186 vs. 319). In females, the proportion supporting severe attitudes changed slightly from $32 \%$ to $30 \%$ (413/1398), $p=0.003$. Females were less willing to reveal a prospective spouse's positive HIV test than males (OR, 0.78; $p=0.003$ ).

By nationality, pre-intervention 38\% (413/1085) of Emiratis and 33\% (267/817) of non-Emiratis expressed severe attitudes. Emiratis were more often (OR, $1.3 ; p=0.02)$ willing to reveal a prospective spouse's HIV positivity compared to other Arabs. This difference disappeared post-intervention $(\mathrm{OR}, 1.0 ; p=0.80)$.

By HIV knowledge scores, pre-intervention, 42\% (195/ $459)$ of students with a higher (> 75\%) HIV knowledge level expressed the intent to report a positive test, versus $34 \%$ $(486 / 1,444)$ with a lower level $(\leq 75 \%)(\mathrm{OR}, 1.5 ; p<0.001)$.

Table 1. Grade 12 students intention to leave the decision on PHT to parents, by sex, nationality, knowledge, and attitude*; pre- and post-educational intervention, Al Ain and Abu Dhabi cities, United Arab Emirates, $2006(n=1858)$

\begin{tabular}{l|c|c|c|c}
\hline \multirow{2}{*}{ Variable } & \multicolumn{2}{|c|}{ Pre-intervention } & \multicolumn{2}{c}{ Post-intervention } \\
\cline { 2 - 4 } & $\mathrm{OR}^{\star * *}$ & $95 \% \mathrm{Cl}^{\star * *}$ & $\mathrm{OR}^{\star * *}$ & $95 \% \mathrm{Cl}^{\star * *}$ \\
\hline Sex (Female) & 1.16 & $0.67-2.14$ & 2.10 & $1.03-4.96$ \\
\hline Nationality (UAE) & 0.95 & $0.66-1.37$ & 1.65 & $0.98-2.78$ \\
\hline Knowledge $(>75 \%)$ & 0.74 & $0.47-1.12$ & 0.64 & $0.38-1.11$ \\
\hline Attitude $(>50 \%)^{* *}$ & 1.12 & $0.80-1.57$ & 0.86 & $0.51-1.48$ \\
\hline
\end{tabular}

${ }^{*}$ Controlling for other variables in the model by multilevel logistic regression with school and division as a grouping factor and random intercept; ** more compassionate, less stigmatizing attitudes; ${ }^{* * *}$ stimated odds ratios and confidence intervals for coefficients

Table 2. Support by grade 12 students for various options in the event of a positive premarital HIV test of a prospective spouse, pre- and post-educational intervention, Al Ain and Abu Dhabi cities, United Arab Emirates, $2006(n=1858)$

\begin{tabular}{|c|c|c|c|c|c|}
\hline \multirow{2}{*}{$\begin{array}{l}\text { Decision given a positive } \\
\text { premarital HIV test }\end{array}$} & \multicolumn{2}{|c|}{ Pre-intervention } & \multicolumn{2}{|c|}{ Post-intervention } & \multirow{2}{*}{$\begin{array}{l}\text { Odds ratios } \\
(95 \% \mathrm{Cls})^{*}\end{array}$} \\
\hline & $n$ & $\%$ & $n$ & $\%$ & \\
\hline Cancel marriage, discuss privately & 1,057 & 56.9 & 1,104 & 59.4 & $1.23(1.02-1.48)$ \\
\hline $\begin{array}{l}\text { Cancel marriage, reveal serology } \\
\text { of proposed spouse }\end{array}$ & 674 & 36.3 & 590 & 31.8 & $0.70(0.55-0.82)$ \\
\hline Marry proposed spouse & 95 & 5.1 & 145 & 7.8 & $1.85(1.33-2.58)$ \\
\hline Other options & 32 & 1.7 & 19 & 1.0 & $0.43(0.18-0.95)$ \\
\hline
\end{tabular}


Post-intervention, the intent to report decreased in both groups (489/1,473; 33\% vs. $110 / 430 ; 26 \%$, OR, $1.4, p=0.002)$; however, the difference between group did not change.

By HIV attitude scores, pre-intervention $42 \%$ of students (376/892) with lower (less compassionate) scores showed a more severe approach to reporting a positive HIV test of a proposed spouse, compared with 30\% (305/1,011) in students with higher scores ( $\geq 50 \%)$. Higher scoring students would less often report (OR, 1.7; $p<0.001)$. This difference increased post-intervention to $46 \%$ among students with lower scores, and decreased to $26 \%$ among those with higher scores (232/504 vs. 367/1,399; OR, 2.4, $p<0.001)$.

Regarding the other factors, with multilevel logistic regression (Table 4), in respect to revealing a prospective spouse's positive HIV result, the intervention eliminated differences concerning sex and nationality. However, while students with higher attitude scores became less likely to report, those with higher knowledge scores became more likely to do so. Attitude and knowledge scores had the greatest impact on intent to report, although in opposite directions. Pre-/post-intervention responses were highly correlated.

\section{Discussion}

\section{Overview of results}

To our knowledge, this is the first study to assess social acceptance of compulsory PHT in the Arab world. Preintervention, the vast majority of students supported PHT of a prospective spouse; $9 \%$ left decisions on testing to family, while post-intervention this value decreased. In the event of a positive HIV test of a prospective spouse, most students would have cancelled the marriage, with one third admitting to openly reveal the test of a prospective spouse; this decreased post-intervention. The willingness to disclose correlated with males, high level of HIV/AIDS knowledge, and negative attitudes towards PLHIV.

\section{Other studies on the acceptance of mandatory PHT}

While our study assessed students' acceptability of compulsory PHT of prospective spouses, some other authors evaluated respondents' opinions on mandatory testing for

Table 3. Grade 12 students intent to reveal information on prospective spouse's HIV seropositivity to the public, pre- and post-intervention by selected variables, Al Ain and Abu Dhabi cities, United Arab Emirates, $2006(n=1887)$

\begin{tabular}{|c|c|c|c|c|c|c|c|c|}
\hline \multirow{2}{*}{ Variable } & \multicolumn{4}{|c|}{ Pre-intervention } & \multicolumn{4}{|c|}{ Post-intervention } \\
\hline & $n$ & Total & $\%$ & $p$ & $n$ & Total & $\%$ & $p$ \\
\hline \multicolumn{9}{|l|}{ Sex } \\
\hline Female & 436 & 1,398 & 32 & \multirow{2}{*}{$<0.001$} & 413 & 1,398 & 30 & \multirow{2}{*}{0.003} \\
\hline Male & 245 & 505 & 49 & & 186 & 505 & 37 & \\
\hline \multicolumn{9}{|l|}{ Nationality } \\
\hline UAE citizens & 413 & 1,085 & 38 & \multirow{2}{*}{0.02} & 344 & 1,085 & 32 & \multirow{2}{*}{0.80} \\
\hline Others & 267 & 817 & 33 & & 254 & 817 & 31 & \\
\hline \multicolumn{9}{|l|}{ Knowledge } \\
\hline$>75 \%$ & 195 & 459 & 42 & \multirow{2}{*}{$<0.001$} & 489 & 1,473 & 33 & \multirow{2}{*}{0.002} \\
\hline$\leq 75 \%$ & 486 & 1,444 & 34 & & 110 & 430 & 26 & \\
\hline \multicolumn{9}{|l|}{ Attitude } \\
\hline$\geq 50 \%$ & 305 & 1,011 & 30 & \multirow{2}{*}{$<0.001$} & 367 & 1,399 & 26 & \multirow{2}{*}{$<0.001$} \\
\hline$<50 \%$ & 376 & 892 & 42 & & 232 & 504 & 46 & \\
\hline
\end{tabular}

Table 4. Grade 12 students intent to report HIV-positive test result of a prospective spouse by sex, nationality, knowledge, and attitude*, pre- and post-educational intervention, Al Ain and Abu Dhabi cities, United Arab Emirates, $2006(n=1879)$

\begin{tabular}{l|c|c|c|c}
\hline \multirow{2}{*}{ Variable } & \multicolumn{2}{|c|}{ Pre-intervention } & \multicolumn{2}{c}{ Post-intervention } \\
\cline { 2 - 4 } & OR*** & $95 \% \mathrm{Cl}^{\star * *}$ & 1.15 & $0.8 \% \mathrm{Cl}$ \\
\hline Sex (Female) & 0.54 & $0.39-0.74$ & 0.84 & $0.67-1.07$ \\
\hline Nationality (UAE) & 1.43 & $1.15-1.78$ & 1.72 & $0.29-2.30$ \\
\hline Knowledge (>75\%) & 1.37 & $1.09-1.72$ & $0.36-0.60$ \\
\hline Attitude $(>50 \%)^{* *}$ & 0.68 & $0.56-0.83$ & 0.46 \\
\hline
\end{tabular}

${ }^{*}$ Controlling for other variables in the model by multilevel logistic regression with school and division as a grouping factor and random intercept; ${ }^{* *}$ more compassionate, less stigmatizing attitudes; ${ }^{* * *}$ estimated odds ratios and confidence intervals for coefficients 
HIV before marriage. Among unmarried Nigerian youths, attitudes were positive towards mandatory testing, with males about twice as likely to support the idea [20]. A majority of Malaysian students approved screening for HIV as a precondition for marriage [21]. However, the acceptance of voluntary HIV testing in China as a standard to premarital counselling was disappointingly low [22]. A study in Malawi found a significant positive association between increased age, urban residence, and the need for confidentiality and willingness to accept voluntary HIV testing prior to marriage. However, knowledge of a person with HIV/ AIDS, HIV testing location, and other sexually transmitted infections as well as belief that abstinence protects against HIV, were inversely related to desire to perform HIV test [23].

\section{Acceptance for PHT of prospective spouses in the context of HIV vulnerability}

Among young Arabs, acceptance was high for compulsory PHT of prospective spouses. Despite Islamic teaching that prohibits sexual intercourse outside a marriage, students may feel vulnerable to HIV, because of poor knowledge regarding HIV transmission and involvement in premarital sex $[2,13]$. In a UNICEF supported study, $3 \%$ of Emirati youths, mainly males, admitted premarital sex. Of those, 30\% reported multiple partners and 7\% to having paid for sex [2]. Studies from other countries in the region indicated greater and increasing premarital sex involvement than among young Emiratis [13]. In a study of a Lebanese university students, $73 \%$ of males and $22 \%$ of females reported having had a sexual relationship prior to the study [12].

\section{Effects of stigma associated with HIV infection}

Stigma drives the HIV/AIDS epidemic by creating a culture of blame and victimization $[4,5,24,25]$. In Nigeria, $44 \%$ of unmarried youth stated that mandatory PHT would increase the stigma of HIV/AIDS [20]. More than one third of students in our survey opted for disclosure of their prospective spouse's HIV sero-positivity, either by informing the public or reporting to police. It is unknown whether students' views were due to Islamic values prohibiting sexual relations before and outside the marriage, or to regional policies such as mandatory HIV testing for several low-risk groups $[8,9,13,26]$. HIV can be seen as divine punishment for deviancy. In Islam, there are greater negative sanctions for prohibited sexual conduct than for drug usage [27]. Expressing empathy and compassion to PLHIV may be perceived as acceptance for a practice that causes the infection $[5,28]$. The degree of stigmatization is reportedly higher in low prevalence areas, which could explain why social stigma is noticeable in a country such as the UAE [26].

More knowledgeable students were more likely to disclose their prospective spouses sero-positive status, and this increased post-intervention (of note, this was an intention to report, not actual reporting behavior). Possibly, as HIV/AIDS knowledge scores improved, misperceptions regarding sources of infection decreased. Students gained information that non marital sex is one of the main modes of HIV transmission for males in the UAE, and that marital sex is the main risk factor for females [1, 14]. Such knowledge, in conjunction with negative religious sanctions for prohibited sexual conduct, might have influenced willingness to reveal a prospective spouse's serology [13, 27]. Attitudes supporting disclosure were associated with negative attitude scores to PLHIV. As found by others, young females had a lower tendency to disclose, possibly due to a more compassionate feminine model of behavior $[24,29]$.

\section{Effects of the educational intervention on stigmatizing attitudes and periodic marital HIV testing}

During our intervention, short workshops were conducted to help students to understand that PLHIV should not be condemned for their illness [14]. Intolerant attitudes towards HIV-infected hypothetical prospective spouses, such as reporting to police or to the public, improved post-intervention. It might be questioned whether this statistically significant change, reported as a proportion, is of actual programmatic significance; however, the study revealed that students with higher attitude scores became less likely to report. Hence, such educational workshops, which appear to be an effective means in reducing discrimination against PLHIV, might also influence PHT in terms of reducing stigmatizing attitudes towards HIV-infected future spouses. Others have reported interventions reducing stigmatizing attitudes and behavior [30, 31]. Post-intervention, supporters of harsh attitudes decreased among males, although general attitude scores improved less than among females [14]. Despite reported challenges in communicating with young males regarding HIV/AIDS related issues [29], appropriate educational interventions may improve negative attitudes [14].

\section{Limitations}

The study included only Abu Dhabi Emirate; however, a strong point of the study was the large number of schools/ classes selected randomly, and the fact that it included also other Arabs. With a substantial proportion of students from other Arab countries, the study may be more broadly generalized within this context. 
The study was completed a number of years ago, with the publication delay resulting from relocations, and communication challenges among contributors due to the variety of locations and distances. However, evidence show that perceptions of young Arabs regarding HIV in 2017 have not shifted to any major extent since the research was completed, and stigma together with a lack of support for PLHIV still persist in the UAE $[32,33]$. Recent reports demonstrate that the cultural situation has not changed in the country during the interval to writing up $[2,32,33]$. In illustration, an Emirati men in his mid 30s with HIV has been waiting more than 15 years to be released from government care because his family won't give their consent, and despite UAE law saying that nationals with HIV should not be detained. $\mathrm{He}$ is not allowed out of confinement without a chaperone, and he was forced to attend his father's funeral in handcuffs [33]. Despite the approval of the law, which gives HIV/AIDS patients equal rights of employment in the UAE, almost all patients are still unemployed due to the stigma, which stops employers from hiring them [34]. Moreover, sadly, only $0.03 \%$ of total AIDS spending in 2012 in the UAE was on HIV health education [2]. Finally, the findings continue to provide useful insights regarding the impact of an educational intervention on premarital HIV testing.

Since the situations presented were hypothetical, one cannot be sure that students would act as declared later in real life. Furthermore, only immediate changes in attitudes and expressed behavior could be assessed.

\section{Conclusions}

High acceptance of compulsory PHT for prospective spouses among young Arabs suggests that they feel vulnerable to HIV before marriage. For those testing positive, results may be socially isolating. Nevertheless, the educational intervention fulfilled its goals, i.e., it was effective in reducing discriminatory attitudes towards PLHIV, and demonstrated the potential to empower young people's knowledge and facilitate sovereign individual decision regarding the PHT of a potential spouse. Although voluntary, confidential PHT has been recommended elsewhere [35], and greater flexibility in national UAE regulations may take time, especially given the high social acceptance of mandatory testing found in our study. Under current legislation, individuals found HIV-positive by PHT are at risk of public disclosure by prospective spouses and resulting social stigmatization. Hence, a challenge for public health practitioners, religious leaders, teachers, and HIV educators will be to contribute in shifting social norms towards greater acceptance of afflicted persons.

Effective education may be supportive of PHT, and should include consideration of prevalent cultural and religious beliefs [8]. Evidence based instruction would inform marriage candidates regarding high-risk behaviors for acquiring HIV, and encourage regular verification of personal serological status for those at risk. Hence, pre-/post-test HIV counselling combined with education is recommended as a basis of PHT. Since more than 18,000 persons undergo mandatory PHT annually in the UAE [2], an effective pre-test counselling itself could be a major preventive intervention.

\section{Acknowledgements}

This work was supported by Research Affairs at the UAE University under individual research grant no. 02-14-8-11/06. We would like to express our appreciations to medical students at the UAE University for their enthusiastic and dedicated work on this project: F. Al-Awadhi, A. Al-Badawy, H. Al-Bolushi, S. Al-Dhaheri, J. Al-Dhahri, A. Al-Jaberi, S. Al-Kaabi, M. Karaji, A. Khouri,H.Al-Kitbi, D. Al-Mansoori, S. Al-Muhairy, W. Al-Neaimi, E. Al-Shamsi, A. Yammahi. Colleagues from various institutions and health authorities were helpful in obtaining information with regard to premarital screening in the UAE: Dr M. Sheek-Hussein, College of Medicine \& Health Sciences, UAE University, Al Ain; Dr R. Al Raei and Dr L. Al Marzooqi from Dubai Health Authority, Dubai; Dr G. Yahia, Health Authority of Abu Dhabi, Al Ain, UAE. $\mathrm{H}$. El Agab at the UAE University helped with data management. We are grateful to the Ministry of Education, schools' principals, teachers, and students for their collaboration.

\section{Conflict of interest}

The authors declared no potential conflicts of interest with respect to the research, authorship, and/or publication of this article.

\section{References}

1. Abu-Raddad LJ, Hilmi N, Mumtaz G, et al. Epidemiology of HIV infection in the Middle East and North Africa. AIDS 2010; 24 (Suppl 2): S5-23.

2. UNAIDS. United Arab Emirates Global AIDS Response Progress Report. 2014: 1-27; available at: http://www.unaids.org/sites/default/files/country/documents/ARE_narrative_report_2014.pdf [Accessed: 9 February 2017].

3. Bozicevic I, Riedner G, Calleja JM. HIV surveillance in MENA: recent developments and results. Sex Transm Infect 2013; 89 (Suppl 3): 11-16.

4. Alkaiyat A, Weiss MG. HIV in the Middle East and North Africa: priority, culture, and control. Int J Pub Health 2013; 58: 927-937.

5. Kamarulzaman A. Fighting the HIV epidemic in the Islamic world. Lancet 2013; 381: 2058-2060.

6. Madani TA, Al Mazrou YY, Al-Jeffri MH, et al. Epidemiology of HIV in Saudi Arabia; 18-year surveillance results and prevention from an Islamic perspective. BMC Infect Dis 2004; 4: 2532.

7. HAAD Standard for Premarital Screening in the Emirate of Abu Dhabi. Version 1.0., Reference: PHP/PMS/V1.0, 2011.

8. Ganczak M. HIV/AIDS education as a supportive tool for premarital HIV screening. J Infect Public Health 2009; 2: 153-154.

9. Hermez J, Petrak J, Karkouri M, et al. A review of HIV testing and counselling policies and practices in the Eastern Mediterranean Region. AIDS 2010 (Suppl 2): S25-32.

10. Alrajhi AA. Premarital HIV screening in Saudi Arabia, is antenatal next? J Infect Public Health 2009; 2: 46.

11. UNAIDS 2014. The Gap Report; available at: http://files.unaids.org/ en/media/unaids/contentassets/documents/unaidspublication/2014/ UNAIDS_Gap_report_en.pdf [Accessed: 9 February 2017]. 
12. Barbour B, Salameh P. Knowledge and practice of university students in Lebanon regarding contraception. East Mediter Health J 2009; 15: 387-399.

13. El-Kak F. Sexuality and sexual health: constructs and expressions in the extended middle East and North Africa. Vaccine 2013; 31 (Suppl 6): G45-50.

14. Barss P, Grivna M, Ganczak M, et al. Effects of a rapid peer-based HIV/AIDS educational intervention on knowledge and attitudes of high-school students in a high-income Arab country. J Acquir Immune Defic Syndr 2009; 52: 86-98.

15. Thomson C, Currie C, Todd J, et al. Changes in HIV/AIDS education, knowledge and attitudes among Scottish 15-16 year old's, 1990-1994: findings from the WHO: Health Behavior in Schoolaged Children Study (HBSC). Health Educ Res 1999; 14: 357-370.

16. R Development Core Team. R: A Language and Environment for Statistical Computing. The R Foundation for Statistical Computing, Vienna 2011; available at: http://www.Rproject.org/ [Accessed: 9 February 2017].

17. Jabbour S, Giacaman R, Khawaja M, et al. Public Health in the Arab World. Cambridge University Press, 2012.

18. C.T. Le Introductory Biostatistics. John Wiley \& Sons, Inc., Hoboken, New Jersey 2003; 314322; available at: http://faculty.ksu.edu. sa/73917/Documents/ BIOSTATISTICS.pdf [Accessed: 9 February 2017].

19. Bates D, Maechler M, Bolker B, et al. lme4: Linear mixed-effects models using Eigen and S4. 2014; available at: http:/CRAN.Rproject. org/package=lme4 [Accessed: 9 February 2017].

20. Arulogun OS, Adefioye OA. Attitude towards mandatory premarital HIV testing among unmarried youths in Ibadan northwest local government area, Nigeria. Afr J Reprod Health 2010; 14: 83-94.

21. Rozina R, Lekhraj R, Lye MS, et al. Knowledge, attitude, and practice related to HIV/AIDS among students in a local university. Malaysian J Med Health Sci 2009; 5: 27-41.

22. Wu Z, Rou K, Lou W, et al. Acceptability of HIV/AIDS counselling and testing among premarital couples in China. AIDS Educ Prev 2005; 17: 12-21.

23. Misiri H, Muula AS. Attitudes towards premarital testing on human immunodeficiency virus infection among Malawians. Croat Med J 2004; 45: 84-87.

24. Monjok E, Smesny A, Essien EJ. HIV/AIDS-related stigma and discrimination in Nigeria: review of research studies and future directions for prevention strategies. Afr J Reprod Health 2009; 13 : 21-35.

25. Abu-Raddad LJ, Ghanem KG, Feizzadeh A, et al. HIV and other sexually transmitted infection research in the Middle East and North Africa: promising progress? Sex Transm Infect 2013; 89 (Suppl 3): 1-4.

26. Akala FA, Jenkins CF. Preventing HIV/AIDS in the Middle East and North Africa: A window of opportunity to act. The International Bank for Reconstruction and Development/The World Bank, 2005.

27. Obermeyer CM. HIV in the Middle East. BMJ 2006; 333: 851-854.

28. Hasnain M. Cultural approach to HIV/AIDS harm reduction in Muslim countries. Harm Reduct J 2005; 2: 23.

29. Ganczak M, Barss P, Alfaresi F, et al. Break the silence: HIV/AIDS knowledge, attitudes, and educational needs among Arab university students in United Arab Emirates. J Adolesc Health 2007; 40: 572.e1-8.

30. Li L, Wu Z, Liang LJ, et al. Reducing HIV-related stigma in health care settings: a randomized controlled trial in China. Am J Public Health 2013; 103: 286-292.

31. Gao X, Wu Y, Zhang Y, et al. Effectiveness of school-based education on HIV/AIDS knowledge, attitude, and behavior among secondary school students in Wuhan, China. PLoS One 2012; 7: e44881.

32. The National. Special report: Emirati HIV sufferer wants help to find a partner. 3 March 2015; available at: http://www.thenational. ae/uae/health/20150303/special-report-emirati-hiv-sufferer-wants -help-to-find-a-partner [Accessed: 9 February 2017].

33. The National. Special report: Emirati man with HIV held for more than a decade at health facility. 3 March 2015; available at: http:// www.thenational.ae/uae/health/20150303/special-report-emirati-man-with-hiv-held-for-more-than-a-decade-at-health-facility [Accessed: 9 February 2017].

34. Emirates News 24/7. Almost all UAE AIDS patients still unemployed, December 20 2010; available at: http://www.emirates247. com/news/emirates/almost-all-uae-aids-patients-still-unemployed-2010-12-20-1.331590 [Accessed: 9 February 2017].

35. Rennie S, Turner AN, Mupenda B, et al. Conducting unlinked anonymous HIV surveillance in developing countries: ethical, epidemiological, and public health concerns. PLoS Med 2009; 6: e4. 